\title{
Ovarian Clear Cell Cystadenofibroma
}

National Cancer Institute

\section{Source}

National Cancer Institute. Ovarian Clear Cell Cystadenofibroma. NCI Thesaurus. Code C40086.

A benign neoplasm of glandular epithelium characterized by the presence of clear or hobnail cells within a dense fibrous stroma and cystic structures. 